\title{
Ribosomal DNA heterochromatin in plants
}

\author{
N. Neves,a,b M. Delgado, a,b M. Silva, ${ }^{a}$ A. Caperta, ${ }^{a, b}$ L. Morais-Cecilioa and \\ W. Viegas ${ }^{a}$ \\ a Secção de Genética, Centro de Botânica Aplicada à Agricultura, Instituto Superior de Agronomia; \\ ${ }^{\mathrm{b}}$ Universidade Lusófona de Humanidades e Tecnologias, Lisboa (Portugal)
}

\begin{abstract}
The aim of this review is to integrate earlier results and recent findings to present the current state-of-theart vision concerning the dynamic behavior of the ribosomal DNA (rDNA) fraction in plants. The global organization and behavioral features of rDNA make it a most useful system to analyse the relationship between chromatin topology and gene
\end{abstract}

expression patterns. Correlations between several heterochromatin fractions and rDNA arrays demonstrate the heterochromatic nature of the rDNA and reveal the importance of the genomic environment and of developmental controls in modulating its dynamics.

Copyright $\odot 2005$ S. Karger AG, Base
Gene function in higher eukaryotes is modulated, amongst other regulatory mechanisms, by the surrounding chromatin in which genes are embedded. At the same time it is also clear that genes constitute just a small fraction of complex genomes, and that most of the DNA that comprises the genome has a noncoding nature. This general feature of eukaryote genomics seems enhanced in plants, since they usually bear larger amounts of non-coding chromatin than many other organisms (Redi et al., 2001; Avramova, 2002). Chromatin has several classes of proteins complexed with its DNA which are responsible for the major levels of its compaction. Of these states of chromatin compaction, one of the most conspicuous to the eye of the cytogeneticist is the fraction that remains highly condensed throughout the cell cycle, the marker that Heitz initially used to define heterochromatin (het; review in Richards and Elgin, 2002). The fact that het is largely the gene-poor fraction

This work results from research projects supported by Fundação para a Ciência e Tecnologia, Portugal (PRAXIS/C/AGR/11171/1998; POCTI/AGR/34000/2000; POCTI/BCI/38557/2001; N.N., M.D., M.S. and A.C.).

Received 23 October 2003; manuscript accepted 19 February 2004.

Request reprints from: Dr. Wanda Viegas, Secção de Genética

Centro de Botânica Aplicada à Agricultura, Instituto Superior de Agronomia

Tapada da Ajuda, PO-1349-017 Lisboa (Portugal)

telephone: +351-21-365-3281; fax: +351-21-363-50 31

e-mail:wandaviegas@isa.utl.pt of the genome (reviews in Redi et al., 2001; Avramova, 2002) mislead many into believing that it represents an "evolutionary relic" maintained in the genome only as a by-product of historical molecular events (John, 1988). During the last 20 years, however, and based on evolutionary genetics and modern molecular approaches, definitive evidence has accumulated to shift the status of het to a role of increasing variability and functional significance. Intense research on the functional genomics of het shows that it plays important roles in the modulation of gene expression, in chromosome structure and in speciation and evolution (reviews in Redi et al., 2001; Avramova, 2002; Richards and Elgin, 2002; Grewal and Moazed, 2003). In this context, and as clearly pointed out by Avramova (2002), coding sequences found in heterochromatin provide our major source of knowledge on the structure and function of this genomic fraction. Accordingly, and considering the het nature of the ribosomal RNA genes that will be discussed, we will draw attention to the relationship between het genomics and the behaviour of ribosomal DNA (rDNA) arrays.

\section{Heterochromatin: nature and functional significance}

Heitz (1928) described het as the genome fraction that is more compact than euchromatin, maintaining high levels of condensation throughout the cell cycle. These densely packed regions in the nucleus are almost exclusively composed of re- 
petitive DNA (Richards and Elgin, 2002), which may also be organized into small het islands not detectable through classical cytogenetic analysis (Kunze et al., 1996; Weichenhan et al., 1998). The het fraction is divided into constitutive het, with a tight chromatin configuration regardless of the cell type in analysis; and facultative het, as the genome fraction that undergoes decondensation and expression in a certain cell lineage but not in other lineages (Avramova, 2002). A classical example of facultative het is the inactive $\mathrm{X}$ chromosome in somatic cells of mammalian females (Boggs et al., 2002). The description of well characterized het islands in Arabidopsis shows that different het fractions are distinct in terms of their molecular, structural and functional organization, thus reflecting the diverse functional activities associated with het (Copenhaver et al., 1999; Fransz et al., 2000; McCombie et al., 2000).

Since blocks of repeats that have nothing obvious in common have the ability to form het, several studies tried to test if the repetitive nature of DNA sequences is itself sufficient to trigger het assembly. Sensitive phenotypic assays for mosaic gene silencing (known as position-effect variegation, PEV) are one of the most widely used systems to evaluate het dynamics and its implication in gene expression. The potent silencing capacity of the het fractions can be exerted by spreading of the tight chromatin configuration of het into adjoining coding sequences (in cis) or by nuclear co-localization between het domains and genes distantly located in the same or at different chromosomes (in trans) (Henikoff, 2000; Richards and Elgin, 2002). Using this system in Drosophila, Henikoff and co-workers demonstrated that at least some repetitive sequences have an innate capacity to promote het formation, affecting PEV phenomena, and showing that enhanced silencing occurs when higher copy number of those sequences are inserted (Dorer and Henikoff, 1994; Henikoff, 2000). Furthermore, transgene arrays induce silencing of nearby endogenous euchromatic genes, indicating that PEV requires only the repeat array itself (Henikoff, 2000). Inactivation of gene expression following gene duplication has also been described in plants (Flavell, 1994). Taken together, these results clearly suggest that repetitiveness alone seems sufficient to promote het formation (Henikoff, 2000).

The chromatin underlying het has several characteristic features, besides its repetitive DNA motifs. The DNA that usually organizes in het is commonly methylated at cytosine residues, which correlates with transcriptional inactivation (review in Martienssen and Colot, 2001). In Arabidopsis, fine mapping of methylated cytosines showed that the density of DNA methylation increases from euchromatin towards pericentromeric het (Mathieu et al., 2002). Particular histone covalent modifications have also been associated with het formation and maintenance. In contrast to euchromatic domains, deacetylation of histone tails and methylation of histone $\mathrm{H} 3$ at lysine 9 (H3mK9) mark a "close" chromatin configuration characteristic of het, which correspond to repressed domains concerning transcription (reviews in Richards and Elgin, 2002; Felsenfeld and Groudine, 2003). Interestingly, several studies in different systems show the interplay of DNA methylation and $\mathrm{H} 3 \mathrm{mK} 9$ methylation in the establishment of het (Johnson et al., 2002; Soppe et al., 2002; Tariq et al., 2003; also reviewed in van Driel et al., 2003). In addition to these chromatin modifications an important role is also played by several protein classes, which are known to establish the nature of het fractions. Of these proteins the best characterized is the heterochromatin-protein 1 (HP1) initially discovered in Drosophila and present in many other eukaryotic systems (Filesi et al., 2001; Grewal and Elgin, 2002; Cheutin et al., 2003). In parallel, recent findings demonstrate the involvement of RNA interference of tandem repeats in the maintenance of het domains (Finnegan and Matzke, 2003; Martienssen, 2003). A cascade of events that involves ATP-dependent protein complexes and integrates both DNA and histone chemical modifications have been proposed, modulating the conversion between eu- and heterochromatin configurations (Grewal and Elgin, 2002).

\section{The heterochromatic nature of ribosomal DNA arrays}

Ribosomal RNAs (rRNAs), together with several classes of protein complexes, build up the translation factory for protein synthesis, the ribosomes. According to their Svedberg coefficient, rRNAs are named as $5 \mathrm{~S}, 5.8 \mathrm{~S}, 18 \mathrm{~S}$ and $25 / 28 \mathrm{~S}(25 \mathrm{~S}$ in plants; 28S in mammals; Sumner, 1990; Pederson and Politz, 2000). Of these, the 5.8, 18 and 25S rRNAs result from splicing of a single $45 \mathrm{~S}$ transcript encoded by rDNA repeated units clustered at particular chromosomal loci the nucleolar organizing regions - NORs (Fig. 1), whereas the 5S rRNA results from transcription of different gene sets located in distinct chromosomal sites (Heslop-Harrison, 2000). For simplicity, and following general literature, rDNA will refer only to the genes coding the $45 \mathrm{~S}$ primary transcript. Transcription of the rDNA gives rise to the most conspicuous nuclear compartment, the nucleolus; hence, the loci where rRNA genes are localized are termed nucleolar organizing regions (McClintock, 1934; review in Pikaard, 2002). The suspension of gene transcription during mitosis results in the disappearance of the nucleolus in late prophase in higher eukaryotes. Nevertheless, the activity of the NOR loci at interphase can often be visualized at the following metaphase as a secondary constriction (McClintock, 1934), thought to reflect the necessary DNA decondensation that allows the access of transcription machinery during interphase (Jimenez et al., 1988). NORs that were engaged in nucleolus formation retain in metaphase some of the proteins, related to rRNA gene transcription (Roussel et al., 1996). The ability of these proteins to reduce silver under acid conditions enables a differential staining of mitotic NORs that were transcribed during the preceding interphase, as well as the staining of nucleoli in interphase nuclei (Goodpasture and Bloom, 1975; Robert-Fortel et al., 1993).

The first key feature that enables the inclusion of the nucleolar organizer regions as het loci is the repetitive nature of the rDNA units. In most eukaryotes the number of rRNA genes is largely redundant in relation to that required to sustain ribosome assemblage; hence only a small fraction of the rDNA units are transcribed (Carmo-Fonseca et al., 2000). In pea, a recent study demonstrated that only about $5 \%$ of the units are transcribed (Gonzalez-Melendi et al., 2001), suggesting that the majority of the rDNA units remain transcriptionally silent. In 
Fig. 1. Organization of the rDNA units at NORs. Note that rDNA units are arranged in tandem in multiple copies at the NOR loci.
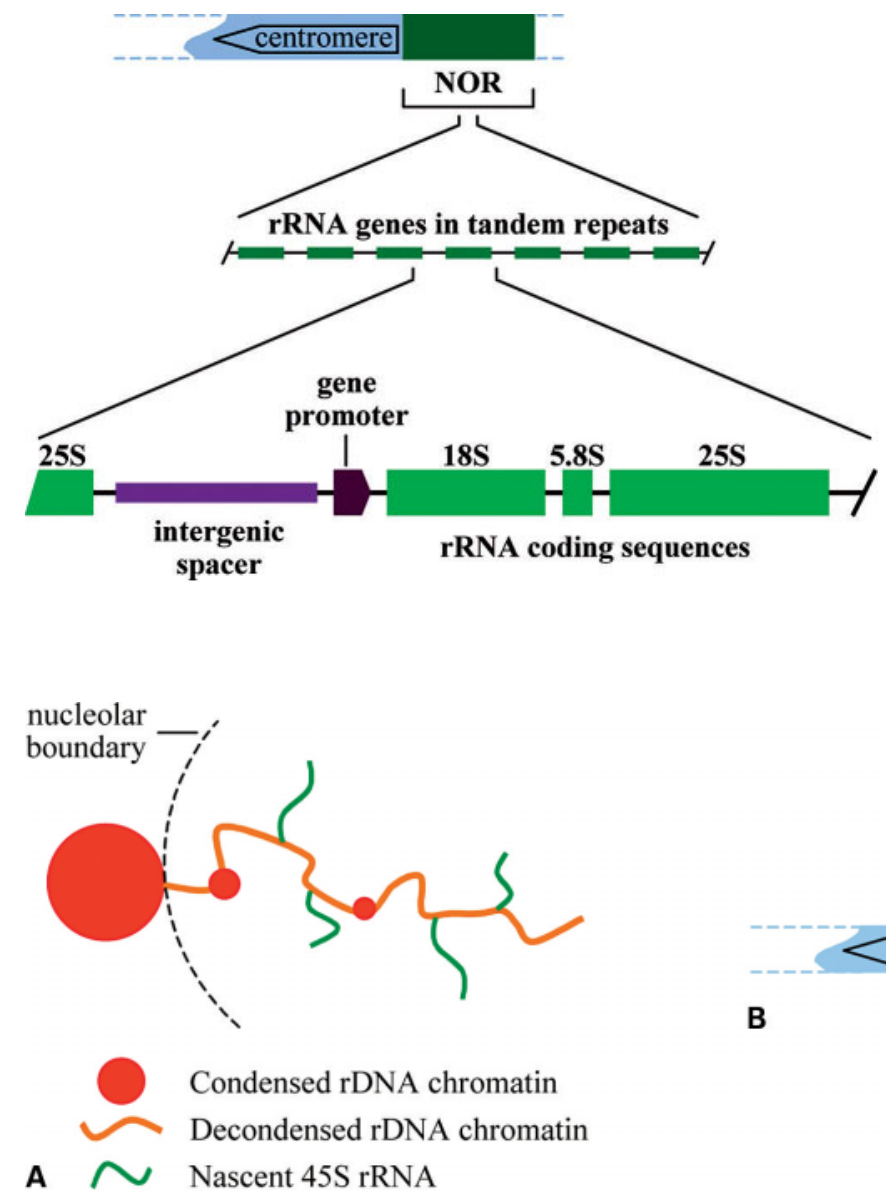

Fig. 2. Organization of the NOR at interphase and metaphase. (A) In interphase cells, most rDNA units remain condensed at the periphery of the nucleolus. The occurrence of intranucleolar condensed rDNA knobs is a species-specific feature. (B) At metaphase, only the centromere-distal NOR domain is revealed by silver staining, indicating previous expression of its rDNA units. many species, this inactivation seems to involve a high level of rDNA chromatin condensation. In situ hybridization with an rDNA probe in interphase nuclei of cereals, pea and Arabidopsis, amongst other species, shows that the condensed rDNA fraction is seen as chromatin blocks at the nucleolar periphery (Fig. 2A; Leitch et al., 1992; Delgado et al., 1995; Shaw and Jordan, 1995; Morais-Cecílio et al., 2000; Pontes et al., 2003). Shaw et al. (1993) have demonstrated in pea that the perinucleolar blocks can undergo decondensation and incorporation into the nucleolus, which is directly related with nucleolar volume and hence, with transcriptional activity. Through BrUTP incorporation assays in wheat, further evidence was obtained that these rDNA knobs are transcriptionally silent (Santos, Silva, Neves, Shaw, and Viegas, manuscript in preparation). Using sequential silver staining and in situ hybridization in rye nuclei it was found that the untranscribed rDNA units always reside at the centromere proximal NOR domain (Fig. 2B; Caperta et al., 2002), as was also reported for Saccharomyces cerevisiae (Buck et al., 2002). Besides conspicuous blocks at the nucleolar boundaries, condensed rDNA chromatin may also appear inside the nucleolus, a feature that seems to be dependent on the species concerned (Fig. 2A). For example, whereas in wheat there are condensed rDNA foci inside the nucleoli (Leitch et al., 1992; Morais-Cecilio et al., 2000; Santos, Silva,



Nucleosome with $\mathrm{H} 3$ non-acetylated and methylated at Lys9

Nucleosome lacking methylation at Lys9 of $\mathrm{H} 3$

— rDNA hypermethylated at the gene promoter

- rDNA undermethylated at the gene promoter

Fig. 3. Epigenetic markers on ribosomal chromatin. Condensed perinucleolar blocks are enriched in histone H3 methylated at lysine 9, and are densely methylated at their rDNA gene promoters. The rDNA units available for transcription have an intranucleolar allocation, and show a low density of cytosine methylation at gene promoters; histone $\mathrm{H} 3$ is barely methylated at lysine 9 . 
Neves, Shaw, and Viegas, manuscript in preparation), such spots are not detected in rye (Delgado et al., 1995; Caperta et al., 2002). In any case, these intranucleolar foci of condensed ribosomal chromatin are also transcriptionally inactive (Santos, Silva, Neves, Shaw, and Viegas, manuscript in preparation), re-enforcing the idea that condensation of rDNA chromatin is tightly related to rRNA gene silencing. These findings are in agreement with the current model for NOR chromatin organization, in which a subset of rRNA genes is tightly packaged and inaccessible to the transcription machinery, whereas another fraction is transcribed (Carmo-Fonseca et al., 2000).

Chromatin modifications that usually mark het, such as cytosine methylation, and post-translational changes in histones, are also found within silenced rRNA gene arrays (Fig. 3). For instance, heavy cytosine methylation is found in NORs, and in several plant systems transcription of rRNA genes seems to occur within gene arrays that are less methylated at their promoters (Jupe and Zimmer, 1993; Neves et al., 1995; Pikaard, 2002). Furthermore, recent findings in Drosophila show that histone modifications characteristic of het, such as $\mathrm{H} 3 \mathrm{mK} 9$, are correlated with silencing of particular NOR loci (Ner et al., 2002).

Findings in mammals revealed that although $\mathrm{H} 3 \mathrm{mK} 9$ is found in both constitutive and facultative het fractions (Peters et al., 2001; Boggs et al., 2002), HP1 does not accumulate at the facultative het (such as in the inactivated $\mathrm{X}$ chromosome in female mammals; Peters et al., 2001). These observations suggest the existence of an HP1-independent pathway intervening in the formation of some facultative het domains. However, indirect evidence of the involvement of HP1 in ribosomal chromatin organization was gained through the discovery in mice and humans of a developmentally regulated protein (ARL5) that interacts with HP1 complexes, and localizes to both nuclei and nucleoli (Lin et al., 2002).

In parallel to what happens in classical het fractions, rDNA arrays are subjected to chromatin remodelling mediated by ATP-dependent engines. Nucleolar remodelling complex (NoRC), a protein complex that includes a chromatin remodelling subunit (Strohner et al., 2001), is responsible for the modulation of rDNA silencing by recruiting DNA methyltransferase and histone deacetylase to the rDNA promoter (Santoro et al., 2002). This concerted action was found to be responsible for establishing the structural characteristics of het, such as DNA methylation, and H3 histone hypoacetylation and methylation of the lysine 9 residue. Taken together, these results indicate that rRNA genes exist in distinct chromatin conformations that can be discriminated by specific epigenetic codes which modulate their expression patterns through the conversion between non-available (het) and potential transcription available configurations. It must however be emphasized that single rRNA genes can be transcribed at equivalent rates to the endogenous tandem arrays, organizing mini-nucleoli (Frieman et al., 1999; Pikaard, 2002). Although these results seem not to support the necessity of a het environment to allow transcription of rRNA genes, it does not rule out the involvement of the het surroundings in the modulation of rDNA expression patterns. This relationship is further sustained by the differential expression of NOR loci observed in both "pure" and polyploid species, as discussed below.

\section{Differential expression of NORs modulated by establishment and maintenance of heterochromatic domains}

One of the most used systems to investigate rRNA genes in active and inactive states are interspecific and intergeneric hybrids. In many of these animal and plant hybrids, only one parental set of rRNA genes retain the ability for nucleolus formation, while the NORs of the other (under-dominant) species are rendered silent, a phenomenon termed nucleolar dominance. This situation was first described in Crepis hybrids by Navashin (1934), and has been the scope of several recent reviews (Pikaard, 2000, 2002; Viegas et al., 2002). The fact that the process does not result from permanent damage of rDNA sequences, as shown by the recovery of activity of under-dominant NORs following appropriate backcrosses (Navashin, 1934; Chen et al., 1998; Pikaard, 1999), demonstrates that we are in the presence of an epigenetic route. Combined molecular and cytogenetic efforts allowed the proposal of several mechanisms for establishing and enforcing nucleolar dominance (review in Viegas et al., 2002). These mechanisms range from the number and size of rRNA intergenic sequences, in that longer spacers would be more effective in titrating the transcription machinery; to concerted/evolutionary divergence of intergenic rDNA sequences and RNA pol I transcription factors in a species-specific manner. Although some experimental data sustain these explanatory mechanisms, there are several cases contradicting the general validity of these models. These "rules and exceptions" have been thoroughly discussed elsewhere (Viegas et al., 2002) and are beyond the scope of this review.

Chromatin modifications such as rDNA promoter methylation and histone acetylation have shown to be integrated into the modulation of rRNA gene activity. In wheat $\times$ rye F1 hybrids, and in its amphiploid triticale, the rye-origin under-dominant NORs are more methylated within intergenic spacer sequences (Neves et al., 1995; Houchins et al., 1997). In Arabidopsis and Brassica hybrids the same happens in the silent NOR loci (Chen and Pikaard, 1997; Chen et al., 1998). Furthermore, seedling treatments with the hypomethylating chemical 5-aza-2'-deoxycytosine (5-AdC) induce reactivation of previously silenced NORs in the wheat-rye system (Vieira et al., 1990; Neves et al., 1995), and also in Arabidopsis (Chen et al., 1998) and Brassica (Chen and Pikaard, 1997) allopolyploids. In Brassica hybrids moreover, it was demonstrated that silent rRNA gene arrays can be reactivated following treatment with the hyperacethylating agent trichostatin (Chen and Pikaard, 1997).

The influence of DNA methylation and histone modifications in the silencing of rRNA genes is however restricted to the chromosome environment. In Brassica hybrids normal and methylated under-dominant rRNA minigenes (cloned in plasmid vectors) have equal capabilities for in vitro transcription (Frieman et al., 1999). In Arabidopsis and Brassica intrageneric hybrids, under-dominant rRNA minigenes are expressed in hybrid protoplasts, whereas the chromosomal copies of these genes remain untranscribed (Chen et al., 1998; Frieman et al., 1999). These results confirm that chromatin-based genetic contents bear an informational charge that marks their expression profiles. 
Considering the exceptions to each of the putative mechanisms involved in the establishment of nucleolar dominance in hybrids, Viegas et al. (2002) recently proposed an unifying model for the initial discrimination between parental sets of rDNA loci. This model arose from the integration of several lines of evidence: (1) higher DNA contents represent higher amounts of repetitive, non-coding sequences (i.e. the same sequences that build up het) (Garagna et al., 1997; Bennetzen, 2000; Redi et al., 2001); (2) repetitive DNA sequences are more effective in titrating het-specific protein complexes, such as HP1 (Grewal and Elgin, 2002; Saveliev et al., 2003); (3) the rDNA fraction is arranged at the NORs, where hundreds to thousands of basic rRNA gene units are repeated in tandem. Furthermore, the presence of two genomes in the same nucleus can be envisioned as adjusting each parental genome to a shared space. Concerning this aspect, it should be stressed that the nuclear volumes of polyploids are usually smaller than the addition of the parental nuclear volumes (e.g. wheat $\times$ rye hybrids; Silva and Viegas, unpublished results). Therefore, if a genome has less space available in the hybrids nucleus, chromatin association is more likely to occur, and to a greater extent in the larger (het richer) genome, establishing a higher level of het-het interactions. Hence, as the model points out, the silenced rDNA belongs always to the larger genome, and the differential expression of rRNA gene sets according to their parental origin is explained in terms of relative het contents of the progenitor species. The model that is consistent with all well described cases of nucleolar dominance (namely in the Triticea, Arabidopsis, Xenopus and Drosophila) makes use of the spatial and functional relation between het fractions that are thoroughly described in many systems. Long-range het interactions leading to gene silencing are found in humans, where inactive genes in pre-B cells associate with het gamma satellite, whereas active B cell genes do not (Brown et al., 1997). Het associations linked to the regulation of gene expression are extremely well documented in Drosophila: for example, both the brown and white gene systems show that silencing is stronger when they are placed together with pericentromeric het (Talbert et al., 1994; Dorer and Henikoff, 1997). Concerning rRNA gene activity, it was shown that Drosophila melanogaster NORs dominate over the rDNA loci of D. simulans in hybrids (Durica and Krider, 1977). However, rearrangements of the het fractions that flank the $D$. melanogaster NORs enable transcription of the under-dominant (D. simulans) rDNA loci, as well as allowing normal expression of the D. melanogaster rRNA gene arrays (Durica and Krider, 1978).

This current model of the primary mechanism establishing nucleolar dominance, along with the results lastly discussed, point out to the functional importance of the het nature of the rRNA gene arrays in the modulation of NOR transcriptional activity.

\section{Functional genomics of the rDNA fraction: the importance of being het}

Recent analysis of the expression and organization of rRNA genes further sustains the view that het genomics can be generally applied to the analysis of the functional organization of the
rDNA fraction. As a first insight to this relation, we may look into the organization and expression of wheat major NORs. Bread wheat is an allohexaploid species composed of three different genomes (A, B and D genomes). The NORs, located on chromosomes $1 \mathrm{~B}$ and $6 \mathrm{~B}$, account for $90 \%$ of the total nucleolar volume in wheat nuclei, and hence are called major NORs (Martini and Flavell, 1985). The 1B loci are responsible for $60 \%$ of the nucleolar mass, and bear half the number of rRNA genes compared with the 6B loci (Flavell and O'Dell, 1976; Flavell, 1986; Sardana et al., 1993). Therefore, the 6B loci have more rDNA repeats and transcribe less, a characteristic common to het fractions. The physical organization of the $1 \mathrm{~B}$ and 6B loci also correlates with this analysis. Mukai et al. (1991), and Morais-Cecílio et al. (2000) have independently shown that at metaphase the $1 \mathrm{~B}$ locus has one centromere-proximal condensed rDNA block, whereas the 6B NOR has two condensed blocks (centromere-proximal and distal blocks). This metaphase configuration of $1 \mathrm{~B}$ and $6 \mathrm{~B}$ NORs also fits with their organization at interphase, as demonstrated by Mukai et al. (1991).

Another line of evidence that brings rDNA functional organization to the level of het genomics is the positional effects in modulating NOR activity. An example of this relation is found in barley where two co-dominant NORs exist, located on chromosomes 6 and 7. In barley lines where these two NORs are located in the same chromosome, due to a translocation involving the two NOR-bearing chromosomes at breakage sites far from the rDNA loci, the NOR 6 becomes dominant (Schubert and Kunzel, 1990). These investigators attribute this result to positional effects that affect transcription of rDNA arrays. More recently Briscoe and Tomkiel (2000) proved that chromosome rearrangements in Drosophila that affect neither copy number nor organization of the rDNA cause a reduction in the amount of rRNA. The addition of $Y$ heterochromatin lacking rDNA arrays suppresses the transcriptional silencing of rRNA genes in a manner that is reminiscent of the PEV phenomena referred earlier. Furthermore, Caperta et al. (2002) found that homologous NORs in rye have differential expression patterns independently of the number of rDNA cistrons. In a chromosome structural variant rye line (used to identify the parental origin of each NOR locus), it was demonstrated that homologous rDNAs have random differential expression, i.e. either one or the other NOR is transcribed at higher levels in each cell (Caperta et al., 2002). It is still unclear whether the random inter-homologous NOR dominance results from differential expression patterns established after each cell division, or from patterns imposed early on in development and then maintained by epigenetic markers, recalling cell mosaicism previously described, namely for PEV phenomena (Platero et al., 1998; Henikoff, 2000). Regardless of the need for tests that will allow discrimination between these two possibilities, it is known that in wheat-rye hybrids the rye-origin NORs remain active following fertilization until the 5th day of embryo development, thereafter being silenced (Castilho et al., 1995; Neves et al., 1997). These results suggest that rDNA differential transcription observed both in diploid and polyploid species may be related to PEV and other het-mediated gene silencing processes, in the sense of being developmentally dependent. 
A more detailed developmental analysis reinforces the link between rDNA and classical het behavior. In Drosophila, Cbands only appear after the blastoderm stage, as no C-bands can be detected on metaphase chromosomes during early embryogenesis (Vlassova et al., 1991). In addition, pattern formation during Drosophila embryogenesis is shown to be under the action of particular protein groups responsible for the establishment of repressive chromatin states (Gould, 1997; Gerasimova and Corces, 1998). Also in plants, the het contents are not static: Ceccarelli and Cionini (1993) showed that the number and size of interphase het domains are related to nuclear functional activity and tissue differentiation. In parallel to this het dynamism associated with developmental progression, nucleolar activity also correlates with cell type and metabolic rates (Carmo-Fonseca et al., 2000; Leitch, 2000). In non-growing cells, rRNA transcription is barely detected, while in growing cells rDNA loci may account for $40-80 \%$ of total transcription (Pikaard, 2002). Growth and hormonal regulation of RNA pol I have also been described in both animals and plants (Jacob, 1995; Gaudino and Pikaard, 1997; Pikaard, 2002). Evaluation of the nucleolar dominance process in plant hybrids also illustrates the characteristic reprogramming of het patterns associated with meiosis. In the wheat-rye system, the under-dominant rye NORs are active in pollen grains following meiotic reprogramming (Silva et al., 1995), and Pikaard and co-workers demonstrated in Brassica hybrids that silent NORs become active in the transition to the floral meristem (review in Pikaard, 2000). Also, the largest nucleoli are formed in wheat haploid microspores (Martini and Flavell, 1985). Therefore, these findings link plant development with large-scale rDNA chromatin remodelling.

After establishing that the regulation of rDNA expression mechanisms matches the het functional genomics, a final note should be added on the biological significance of rDNA silencing. In baker's yeast ( $S$. cerevisiae) the importance of rDNA silencing is involved with silencing of transposable elements that integrate into the NOR loci (Bryk et al., 1997); and with suppression of rDNA recombination (Gottlieb and Esposito, 1989), as also found in higher eukaryotes (Akhmanova et al., 2000; Carmo-Fonseca et al., 2000; Pikaard, 2002). Another emerging role for rDNA silencing is in the regulation of cellular life span, where both features are associated in yeast with Sir2 protein dosage (Guarente, 2000). The Sir2 protein is a histone deacetylase that makes part of the RENT complex that is required for rDNA silencing, causing tight chromatin configurations (Straight et al., 1999). In Caenorhabditis elegans, increased dosage of SIR2 also extends organism life span (Tissenbaum and Guarente, 2001). Hence, the het nature of the rDNA may have a highly conserved function in life span and aging through the modulation of a specialized ribosomal chromatin structure (Buck et al., 2002).

Similar pathways in the plant kingdom have not yet been analyzed. Nevertheless, it was recently found that the condensed pattern of rye rDNA characteristic of meristematic root cells from young wheat-rye hybrid seedlings is modified in the meristematic root cells of older plants (Silva and Viegas, unpublished data). This aging-modulated change in ribosomal chromatin configuration is associated with an increase in nuclear area, indicating a regulation checkpoint that involves overall chromatin compaction. Interestingly, as early as in 1934 Navashin reported that chromosomes are shorter in embryonic Crepis roots than in adult roots. These findings disclose for the first time a correlation between het dynamics and aging phenomena in plants, and reinforce the interest in continuing the analysis of the rDNA fraction as an effective model for understanding chromatin remodelling processes associated with developmental cues and epigenetics.

\section{Acknowledgements}

We are most grateful to Prof. Neil Jones for critical review of the manuscript.

\section{References}

Akhmanova A, Verkerk T, Langeveld A, Grosveld F, Galjart N: Characterisation of transcriptionally active and inactive chromatin domains in neurons. $\mathrm{J}$ Cell Sci 113:4463-4474 (2000).

Avramova ZV: Heterochromatin in animals and plants. Similarities and differences. Plant Phys 129: 40-49 (2002).

Bennetzen JL: The many hues of plant heterochromatin. Genome Biol 1: REVIEWS107 (2000).

Boggs BA, Cheung P, Heard E, Spector DL, Chinault AC, Allis CD: Differentially methylated forms of histone $\mathrm{H} 3$ show unique association patterns with inactive human $\mathrm{X}$ chromosomes. Nat Genet 30: 73-76 (2002).

Briscoe A Jr, Tomkiel JE: Chromosomal position effects reveal different cis-acting requirements for rDNA transcription and sex chromosome pairing in Drosophila melanogaster. Genetics 155:11951211 (2000).

Brown KE, Guest SS, Smale ST, Hahm K, Merkenschlager M, Fisher AG: Association of transcriptionally silent genes with Ikaros complexes at centromeric heterochromatin. Cell 91:845-854 (1997).
Bryk M, Banerjee M, Murphy M, Knudsen KE, Garfinkel DJ, Curcio MJ: Transcriptional silencing of Ty1 elements in the RDN1 locus of yeast. Genes Dev 11:255-269 (1997).

Buck SW, Sandmeier JJ, Smith JS: RNA polymerase I propagates unidirectional spreading of rDNA silent chromatin. Cell 111:1003-1014 (2002)

Caperta A, Neves N, Morais-Cecílio L, Malhó R, Viegas $\mathrm{W}$ : Genome restructuring in rye affects the expression, organization and disposition of homologous rDNA loci. J Cell Sci 115:2839-2846 (2002)

Carmo-Fonseca M, Mendes-Soares L, Campos I: To be or not to be in the nucleolus. Nat Cell Biol 2:107112 (2000).

Castilho A, Queiroz A, Silva M, Barão A, Neves N, Viegas $\mathrm{W}$ : The developmental stage of inactivation of rye origin rRNA genes in the embryo and endosperm of wheat $\times$ rye F1 hybrids. Chromosome Res 3:169-174 (1995).

Ceccarelli M, Cionini PG: Tissue-specific nuclear repatterning in plant cells. Genome 36:1092-1098 (1993).
Chen J, Comai L, Pikaard C: Gene dosage and stochastic effects determine the severity and direction of uniparental rRNA gene silencing (nucleolar dominance) in Arabidopsis allopolyploids. Proc Nat Acad Sci USA 95:14891-14896 (1998).

Chen ZJ, Pikaard CS: Epigenetic silencing of RNA polymerase I transcription: a role for DNA methylation and histone modification in nucleolar dominance. Gene Dev 11:2124-2136 (1997).

Cheutin T, McNairn AJ, Jenuwein T, Gilbert DM, Singh PB, Misteli T: Maintenance of stable heterochromatin domains by dynamic HP1 binding. Science 299:721-725 (2003).

Copenhaver GP, Nickel K, Kuromori T, Benito M-I, Kaul S, Lin X, Bevan M, Murphy G, Harris B, Parnell LD, McCombie WR, Martienssen RA, Marra M, Preuss D: Genetic definition and sequence analysis of Arabidopsis centromeres. Science 286 2468-2474 (1999).

Delgado M, Morais-Cecílio L, Neves N, Jones RN, Viegas W: The influence of $\mathrm{B}$ chromosomes on rDNA organization in rye interphase nuclei. Chromosome Res 3:487-491 (1995). 
Dorer DR, Henikoff S: Expansions of transgene repeats cause heterochromatin formation and gene silencing. Cell 77:993-1002 (1994).

Dorer DR, Henikoff S: Transgene repeat arrays interact with distant heterochromatin and cause silencing in cis and trans. Genetics 147:1181-1190 (1997).

Durica DS, Krider HM: Studies on the ribosomal RNA cistrons in interspecific Drosophila hybrids. I. Nucleolar dominance. Dev Biol 59:62-74 (1977).

Durica DS, Krider HM: Studies on the ribosomal RNA cistrons in interspecific Drosophila hybrids. II. Heterochromatic regions mediating nucleolar dominance. Genetics 89:37-64 (1978).

Felsenfeld G, Groudine M: Controlling the double helix. Nature 421:448-453 (2003)

Filesi I, Cardinale A, van der Sar S, Cowell IG, Singh PB, Biocca S: Loss of Heterochromatin Protein 1 (HP1) chromodomain function in mammalian cells by intracellular antibodies causes cell death. J Cell Sci 115:1803-1813 (2001)

Finnegan EJ, Matzke MA: The small RNA world. J Cell Sci 116:4689-4693 (2003).

Flavell RB: The structure and control of expression of ribosomal RNA genes. Oxford Surv Pl Mol Cell Biol 3:251-273 (1986)

Flavell RB: Inactivation of gene expression in plants as a consequence of specific sequence duplication. Proc Natl Acad Sci USA 91:3490-3496 (1994).

Flavell RB, O'Dell M: Ribosomal RNA genes on homoeologous chromosomes of groups 5 and 6 in hexaploid wheat. Heredity 37:377-385 (1976).

Fransz PF, Armstrong A, de Jong JH, Parnell LD, van Drunen C, Dean C, Zabel P, Bisseling T, Jones $\mathrm{GH}$ : Integrated cytogenetic map of chromosome arm $4 \mathrm{~S}$ of $A$ thaliana: structural organization of heterochromatic knob and centromere region. Cell 100:367-376 (2000).

Frieman M, Chen ZJ, Saez-Vasquez J, Shen LA, Pikaard CS: RNA polymerase I transcription in a Brassica interspecific hybrid and its progenitors: tests of transcription factor involvement in nucleolar dominance. Genetics 152:451-460 (1999).

Garagna S, Perez-Zapata A, Zuccotti M, Mascheretti S, Marziliano N, Redi CA, Aguilera M, Capanna E: Genome composition in Venezuelan spiny-rats of the genus Proechimys (Rodentia, Echimyidae). I. Genome size, C-heterochromatin and repetitive DNAs in situ hybridization patterns. Cytogenet Cell Genet 78:36-43 (1997).

Gaudino RJ, Pikaard CS: Cytokinin induction of RNA polymerase I transcription in Arabidopsis thaliana. J Biol Chem 272:6799-6804 (1997).

Gerasimova TI, Corces VG: Polycomb and trithorax group proteins mediate the function of a chromatin insulator. Cell 92:511-521 (1998).

González-Melendi P, Wells B, Beven A, Shaw PJ: Single ribosomal transcription units are linear, compacted Christmas trees in plant nucleoli. Plant J 27:223-233 (2001)

Goodpasture C, Bloom SE: Visualization of nucleolar organizer regions in mammalian chromosomes using silver staining. Chromosoma 53:37-50 (1975).

Gottlieb S, Esposito RE: A new role for a yeast transcriptional silencer gene, SIR2, in regulation of recombination in ribosomal DNA. Cell 56:771776 (1989)

Gould A: Functions of mammalian Polycomb group and trithorax group related genes. Curr Opin Genet Dev 7:488-494 (1997).

Grewal SIS, Elgin SCR: Heterochromatin: New possibilities for the inheritance of structure. Curr Opin Genet Dev 12:178-187 (2002).

Grewal SI, Moazed D: Heterochromatin and epigenetic control of gene expression. Science 301:798-802 (2003).

Guarente L: Sir2 links chromatin silencing, metabolism, and aging. Genes Dev 14:1021-1026 (2000).
Heitz E: Das Heterochromatin der Moose I. Jahrb Wiss Biol 69:762-818 (1928).

Henikoff S: Heterochromatin function in complex genomes. Biochem Biophys Acta 1470:1-8 (2000).

Heslop-Harrison JS: Comparative genome organization in plants: from sequence and markers to chromatin and chromosomes. Plant Cell 12:617-635 (2000).

Houchins K, O’Dell M, Flavell RB, Gustafson JP Cytosine methylation and nucleolar dominance in cereal hybrids. Mol Gen Genet 255:294-301 (1997)

Jacob ST: Regulation of ribosomal gene transcription. Biochem J 306:617-626 (1995).

Jimenez R, Burgos M, Diaz de la Guardia RA: Study of the Ag-staining significance in mitotic NORs. Heredity 60:125-127 (1988)

John B: The biology of heterochromatin, in Verma S (ed): Heterochromatin, pp 1-147 (Cambridge University Press, Cambridge 1988).

Johnson L, Cao X, Jacobsen S: Interplay between two epigenetic marks: DNA methylation and histone H3 lysine 9 methylation. Curr Biol 12:1360-1367 (2002).

Jupe ER, Zimmer EA: DNase I sensitive and undermethylated rDNA is preferentially expressed in a maize hybrid. Plant Mol Biol 21:805-821 (1993).

Kunze B, Weichenhan D, Virks P, Traut W, Winking $\mathrm{H}$ : Copy numbers of a clustered long-range repeat determine C-band staining. Cytogenet Cell Genet 73:86-91 (1996)

Leitch AR: Higher levels of organization in the interphase nucleus of cycling and differentiated cells. Micro Mol Biol Rev 64:138-152 (2000).

Leitch AR, Mosgoller W, Shi M, Heslop-Harrison JS: Different patterns of rDNA organization at interphase nuclei of wheat and rye. J Cell Sci 101:751757 (1992).

Lin CY, Li CC, Huang PH, Lee FJ: A developmentally regulated AFR-like 5 protein (ARL5), localized to nuclei and nucleoli, interacts with heterochromatin. J Cell Sci 115:4433-4445 (2002).

Martienssen R: Maintenance of heterochromatin by RNA interference of tandem repeats. Nat Genet 35:213-214 (2003)

Martienssen R, Colot V: DNA methylation and epigenetic inheritance in plants and fungi. Science 293: 1070-1074 (2001).

Martini G, Flavell R: The control of the nucleolus volume in wheat, a genetic study of three developmental stages. Heredity 54:111-120 (1985).

Mathieu O, Picard, G, Tourmante S: Methylation of a euchromatin-heterochromatin transition region in Arabidopsis thaliana chromosome 5 left arm. Chromosome Res 10:455-466 (2002).

McClintock B: The relationship of a particular chromosomal element to the development of the nucleoli in Zea mays. Z Zellforch Mikrosk Anat 21:294328 (1934).

McCombie WR, et al: The complete sequence of a heterochromatic island from a higher eukaryote. Cell 100:377-386 (2000)

Morais-Cecilio L, Delgado M, Jones RN, Viegas W Modification of wheat rDNA loci by rye B chromosomes: a chromatin organization model. Chromosome Res 8:341-351 (2000).

Mukai Y, Endo TR, Gill BS: Physical mapping of the 18S 26S rRNA multigene family in common wheat: identification of a new locus. Chromosoma 100:71-78 (1991).

Navashin M: Chromosomal alterations caused by hybridization and their bearing upon certain general genetic problems. Cytologia 5:169-203 (1934).

Ner SS, Harrington MJ, Grigliatti TA: A role for the Drosophila SU(VAR)3-9 protein in chromatin organization at the histone gene cluster and in suppression of position-effect variegation. Genetics 162:1763-1764 (2002)
Neves N, Heslop-Harrison JS, Viegas W: rRNA gene activity and control of expression mediated by methylation and imprinting during embryo development in wheat $\times$ rye hybrids. Theor Appl Genet 91:529-533 (1995).

Neves N, Castilho A, Silva M, Heslop-Harrison JS, Viegas W: Genomic interactions: gene expression, DNA methylation and nuclear architecture. Chromosomes Today 12:182-200 (1997).

Pederson T, Politz JC: The nucleolus and the four ribonucleoproteins of translation. J Cell Biol 148: 1091-1095 (2000)

Peters AHFM, Mermoud JE, O'Carroll D, Pagani M, Schweizer D, Brockdorff N, Jenuwein T: Histone $\mathrm{H} 3$ lysine 9 methylation is an epigenetic imprint of facultative heterochromatin. Nat Genet 30:77-80 (2001).

Pikaard CS: Nucleolar dominance and silencing of transcription. Trends Plant Sci 12:478-483 (1999).

Pikaard CS: The epigenetics of nucleolar dominance. Trends Genet 16:495-500 (2000).

Pikaard CS: Transcription and tyranny in the nucleolus: the organization, activation, dominance, and repression of ribosomal RNA genes, in Somerville CR, Meyerowitz EM (eds): The Arabidopsis Book (American Society of Plant Biologists, Rockville MD 2002)

Platero JS, Csink AK, Quintanilla A, Henikoff S Changes in chromosomal localization of heterochromatin-binding proteins during the cell cycle in Drosophila. J Cell Biol 140:1297-1306 (1998).

Pontes O, Lawrence RJ, Neves N, Silva M, Lee J-H, Chen ZJ, Viegas W, Pikaard CS: Natural variation in nucleolar dominance reveals the relationship between nucleolus organizer chromatin topology and rRNA gene transcription in Arabidopsis. Proc Natl Acad Sci USA 100:11418-11423 (2003).

Redi CA, Garagna S, Zacharias H, Zuccotti M, Capanna E: The other chromatin. Chromosoma 110 136-147 (2001).

Richards EJ, Elgin SCR: Epigenetic codes for heterochromatin formation and silencing: rounding up the usual suspects. Cell 108:489-500 (2002).

Robert-Fortel I, Junéra HR, Géraud G, HernandezVerdun D: Three-dimensional organization of the ribosomal genes and Ag-NOR proteins during interphase and mitosis in PtK1 cells studied by confocal microscopy. Chromosoma 102:146-157 (1993).

Roussel P, Andre C, Comai L, Hernandez-Verdun D The rDNA transcription machinery is assembled during mitosis in active NORs and absent in inactive NORs. J Cell Biol 133:235-246 (1996).

Santoro R, Li J, Grummt I: The nucleolar remodeling complex NoRC mediates heterochromatin formation and silencing of ribosomal gene transcription. Nat Genet 32:393-396 (2002).

Sardana R, O’Dell M, Flavell RB: Correlation between the size of the intergenic regulatory region, the status of cytosine methylation of rRNA genes and nucleolar expression in wheat. Mol Gen Genet 236:155-162 (1993)

Saveliev A, Everett C, Sharpe T, Webster Z, Festenstein R: DNA triplet repeats mediate heterochromatin-protein-1-sensitive variegated gene silencing. Nature 422:909-913 (2003).

Schubert I, Kunzel G: Position-dependent NOR activity in barley. Chromosoma 99:352-359 (1990).

Shaw PJ, Jordan EG: The nucleolus. Annu Rev Cell Devel Biol 11:93-121 (1995).

Shaw PJ, Rawlins DJ, Highett MI: Nuclear and nucleolar structure in plants, in Heslop-Harrison JS, Flavell RB (eds): John Innes Review - The Chromosome, pp 161-171 (Bios Scientific Publishers, Oxford 1993). 
Silva M, Queiroz A, Neves N, Barão A, Castilho A, Morais-Cecílio L, Viegas W: Reprogramming of rye rDNA in triticale during microsporogenesis. Chromosome Res 3:492-496 (1995)

Soppe W, Jasencakova JZ, Houben A, Kakutani T, Meister A, Huang MS, Jacobsen SE, Schubert I, Fransz PF: DNA methylation controls histone H3 lysine 9 methylation and heterochromatin assembly in Arabidopsis. EMBO J 21:6549-6559 (2002).

Straight AF, Shou W, Dowd GJ, Turck CW, Deshaies RJ, Johnson AD, Moazed D: Net1, a Sir2-associated nucleolar protein required for rDNA silencing and nucleolar integrity. Cell 97:245-256 (1999).

Strohner R, Nemeth A, Jansa P, Hofmann-Rohrer U, Santoro R, Langst G, Grummt I: NoRC - novel member of mammalian ISWI-containing chromatin remodeling machines. EMBO J 20:4892-4900 (2001).
Sumner AT: Nucleolar organizers (NORs), in: Chromosome Banding, pp 187-205 (Unwin Hyman Ltd London 1990).

Talbert PB, Leciel CDS, Henikoff S: Modification of the Drosophila heterochromatic mutation brownDominant by linkage alterations. Genetics 136:559-571 (1994).

Tariq M, Saze H, Probst AV, Lichota J, Habu Y, Paszkowski J: Erasure of CpG methylation in Arabidopsis alters patterns of histone $\mathrm{H} 3$ methylation in heterochromatin. Proc Natl Acad Sci USA 100: 8823-8827 (2003).

Tissenbaum HA, Guarente L: Increased dosage of a sir2 gene extends lifespan in Caenorhabditis elegans. Nature 410:227-230 (2001).

van Driel R, Fransz PF, Verschure PJ: The eukaryotic genome: a system regulated at different hierarchical levels. J Cell Sci 116:4067-4075 (2003).
Viegas W, Neves N, Silva M, Caperta A, Morais-Cecílio L: Nucleolar dominance: a "David and Goliath" chromatin imprinting process. Curr Genomics 3:563-576 (2002)

Vieira R, Queiroz Á, Morais L, Barão A, Mello-Sampayo $\mathrm{T}$, Viegas $\mathrm{W}$ : $1 \mathrm{R}$ chromosome nucleolus organizer region activation by 5-azacytidine in wheat-rye hybrids. Genome 33:707-712 (1990).

Vlassova IE, Graphodatsky AS, Belyaeva ES, Zhimulev IF: Constitutive heterochromatin in early embryogenesis of Drosophila melanogaster. Mol Gen Genet 229:316-318 (1991).

Weichenhan D, Kunze B, Traut W, Winking H: Evolution by fusion and amplification: the murine Sp100-rs gene cluster. Cytogenet Cell Genet 80: 226-231 (1998). 
Copyright: S. Karger AG, Basel 2005. Reproduced with the permission of S. Karger AG, Basel. Further reproduction or distribution (electronic or otherwise) is prohibited without permission from the copyright holder. 
Copyright: S. Karger AG, Basel 2005. Reproduced with the permission of S. Karger AG, Basel. Further reproduction or distribution (electronic or otherwise) is prohibited without permission from the copyright holder. 